\title{
Pedro Lessa e João Mendes Junior
}

Na noite de 19 de dezembro de 1923, quando se efetuava, no velho edificio da Faculdade de Direito, a "festa da chave", realizouse, tambem, a cerimonia da entrega dos bustos dos inesqueciveis mestres Pedro Lessa e João Mendes Junior à Escola do Largo de São Francisco. Foi uma solenidade de expressiva significação e à qual presidiu o professor Reinaldo Porchat, tendo a seu lado os lentes da Congregação, os representantes das altas autoridades de São Paulo e o Dr. Mora y Araujo, embaixador argentino. A assistencia era enorme, constituida de alunos, advogados, desembargadores, etc.

Falaram, na ocasião, diversos oradores. Das alocuções feitas, destacamos as de autoria dos professores Waldemar Ferreira e SpenCER VAMPRÉ, o primeiro em nome dos antigos alunos e promotores da homenagem, e o segundo externando o agradecimento da Faculdade. Ficam, agora, nas paginas desta "Revista", como das mais belas reminiscencias em memoria dos catedraticos então consagrados.

Discurso do professor Waldemar FerReira:

Não disfarço a emoção com que, passados quinze anos, volto a esta tribuna. Nela proferi o meu ultimo discurso acadêmico, quando a minha turma, em solenidade, que ficou memoravel, mêrce do concurso da palavra de Enrico FErri, entregava à que lhe sucedia, a chave simbólica das tradições desta casa augusta e quasi centenaria.

Recordar é viver outra vez, reproduzindo imagens que não nos sáem da memória, reavivando paizagens, recompondo acontecimentos, restabelecendo estados dalma. Trabalho suavíssimo é esse, no qual não se sabe se maior é o contingente do cérebro ou o do coração. Palhetadas rapidas, matizes esbatidos, sonoridades emudecidas, palavras, gestos, sentimentos, pequeninos pezares, alegrias infinitas, tudo isso, num momento, como se dispuzessemos de varetas mágicas, se move, se anima, vibra e canta. 
Atraves da lente reconstrutora da saudade, revejo os bons tempos, que não voltam mais. A saudade opéra milagres. Caminhando sempre para a frente, levamos o passado nos olhos e nos ouvidos. Daí a afirmação de que não ha passado: tudo é presente. Ilusão dos sentidos...

Aquí tenho diante dos olhos figuras que não mais se esquecem; nos ouvidos, nomes e verbos, cuja eloquência o tempo não apaga de vez porque o seu éco caminha no tropel das gerações.

Quem teve a felicidade de passar por este velho mosteiro, em cujas arcadas se formam almas, educam-se espiritos, e se fórma o espirito nacional, ha de sentir, em momento como este, que aqui se não perde a lembrança dos que, com a galhardia dos heróis e a convicção dos sabios, contribuiram para que o nosso país realizasse as suas mais altas aspirações.

\section{O MOMENTO}

A onda de pessimismo amargo, que a literatura doentia dos livros de capa amarela avolumou, a princípio não foi mais do que simulácro de manifestação superior de cultura nova, dissimulada em humorismo de imitação. Depois, o veio pequenino borbulhou, rodou, engrossou, correu, e alagou os espiritos.

Não mais confiando em si mesmos, os homens, com maioria de razão, descreram dos seus semelhantes. Na sua descrença, negaram, desbarataram o nosso patrimônio moral e começaram de descarnar o cerne de nossa nacionalidade, que se foi depauperando em esvaimento paulatino, de gota em gota.

Chegámos, assim, ao momento atual, de desordem intelectual e moral, profundamente alterada por outra desordem maior, financeira e econômica, de câmbio miseravel, intervenções descabidas nos Estados, desequilibrio, anormalidades que estado de sitio, longo como a nossa paciência, tornou quasi normais, por inversão das coisas. De politica pequenina, que não é filha da moral, nem da razão, 
não podia sair senão administração incolor, sem roteiro e. sem lei, cujo programa se desdobra em medidas passageiras, de experiências sucessivas e desastradas, de empirismo primitivo.

A impressão, que, à primeira vista, se tem, diante de tal estado de coisas, é que a nossa maior crise é a de homens afeitos à administração pública, nos seus varios ramos.

Anos atrás, da independência ao advento republicano, ao redor do trôno se moviam estadistas, notaveis pelo saber e pela honra, muitos dos quais, sózinhos, valiam por épocas inteiras. Implantado o regimen democratico, desapareceram nas dobras da mortalha que envolveu o Imperio. Muitos, fieis ao regíme decaído, mesmo no sể isolamento, ficaram dignos da gratidão dos brasileiros. Outros, em pleno regíme republicano, Rio Branco e Nabuco à frente, ganharam novo relevo, enchendo-se de novas glorias.

Na consolidação do novo regíme, que passou a viver sem partidos, a escalada aos altos postos obedeceu, salvo poucas exceções, e essas honrosissimas, mais ao criterio das necessidades e conveniências partidarias que ao das necessidades e conveniências do país.

De onde se segue que a crise de homens, que nos assoberba, não é, não póde ser crise nacional. A crise se manifestou, e se torna cada vez mais aguda, não ha como dizer a verdade inteira! nas fileiras partidarias, onde vai grande dissidio, mercê do qual, pela imprensa, pela tribuna parlamentar, e até pelos documentos oficiais, uns aos outros se arrazam, descambando todos, ao fim, para a vala comum dos vencidos.

Bastaria, apenas, em tão singular emergência, que, reatando o fio de nossas tradições, pondo em cada lugar os mais competentes, os mais dignos, nós, que temos feito a valorização do café, do algodão, da borracha, do assucar e, até, a do boi, nos empenhassemos em campanha de valorização de nossos homens. Mas, bem entendido, valorização dos de pêso e medida, dos que, na bolsa dos valores morais e econômicos, fossem de tipo quatro para cima. Porque, para os tipos inferiores, que poderiamos chamar o tipo 
“"escolha", para esses, destinados à torrefação em casa, a valorização seria, decididamente, inútil.

\section{DUAS HOMENAGENS}

A morte é a grande niveladora, no mundo biológico. No mundo moral, mesmo aqueles que não admitem a teoria da metempsicóse, admitem a sobrevivência dos grandes nomes. Morrem os homens, mas os seus feitos perduram, as suas obras sobrevivem, os seus exemplos frutificam.

Não devemos, portanto, permitir que as pedras, que fecham os tumulos, abafem a sobrevida dos nossos grandes homens, dos que se dedicaram, com todo o seu desinterềsse, ao nosso país. Além da vida objetiva, está a subjetiva. Ha nomes impereciveis, idolos que devem sempre acompanhar as gerações, para que, voltando o futuro os olhos para o passado, sinta a solidez da base de sua grandeza.

Ao mesmo tempo que tiveram os antigos discipulos e amigos de Pedro Lessa, entre os quais me inscrevi, a lembrança feliz de trazer para este salão o busto em bronze daquele grande magistrado, cuja perda ainda lamentamos, porque agora, mais do que nunca, careciamos do amparo e da vigilância daquela inteligência poderosa, que a coragem e a confiança em si mesmo e em nosso país tornaram força consideravel - pareceu ao Instituto da Ordem dos Advogados de São Paulo, em nome do qual vos falo, que devia tambem trazer para esta sala o busto em bronze de Jo:̃o Mendes DE Almeida Junior, cultuando a memoria deste grande jurisconsulto e, ao mesmo passo, homenageando esta gloriosa Academia de Direito, berço de nossa educação jurídica, de onde sairam e hão de saír os nomes nacionais, e da qual ele foi professor e diretor.

Igualam-se, destarte, na nossa veneração, os dois professores que, na mais alta corporação judiciária do Brasil, foram dos mais belos exemplos da nossa cultura juridica. 


\section{HOMEM DE LEI}

Vivendo vida simples, ao influxo de suas convicçõe religiosas, que a sua doutrina filosófica exaltou, JoÃo MENDES Junior foi, em toda a extensão da palavra, homem de lei. No meio de seus livros, crescendo, cada dia, as suas preocupações intelectuais; dedicando-se, de corpo e alma, ao estudo do fenómeno jurídico; e afastando-se, por inclinação irresistivel, do grande mundo, onde, com boas maneiras e punhos de renda, na róca das perversidades individuais, se tecem intrígas, as que provocam sorrisos, e as que provocam lágrimas, ele viveu a vida dos sábios e dos santos. Não odiou. Não praticou o mal. Não cortejou. Não dobrou a cerviz. Não converteu as suas convicções na moéda corrente do interêsse.

Passou, através das multidões, como humilde, mas como iluminado. Não obstante a côifa, com que se vestiu, de imensa modéstia, o seu prestigio pessoal era inconfundivel.

Se, como disse Gladstone, o lêma dos grandes homens deve ser o de não esquecer nunca, embora perdoando sempre, o de JoÃo Mendes Junior, como o indica a sua bondade, não devia ter sido outro.

Porque ele havia, necessariamente, de ter sofrido os golpes da maldade humana.

E perdoou.

\section{o PROFESSOR}

Professor de direito, ele o foi, e dos mais respeitados. Professor de verdade, conhecía o direito e o lecionava com largueza de vistas fóra do comum.

Escrevendo sobre o ensino superior em Portugal, notou Fialho de Almeida que lá estava perdida a tradição dos grandes professores, em palavras deste naipe:

"Já não há professores, mas diletantes, que salvo exceções, são políticos de carreira, diretores de companhias, 
negociantes de vinhos, jornalicastros, ou "dandies" esportmaniâcos, pessoas, emfim, gomosas e universais, da mediocridade arrivista dos topa-a-tudo, gosando de ilustre fama por se exhibirem de sábios nas assembléias dos algodões lavados e dos trigos, ou de algodoeiros e moageiros nas perlêndas da cátedra cientifica".

"Na maioria dos casos a ciência não é tida como um sacerdócio, mas como um modo de vida, exercido na proporção do pouco que rende. Cerío haverá professores austéros e escrupulosos (ninguem duvida), mas o dominante $\dot{e}_{i}$ debitarem as lições a frio, de relogio na mesa, e pensando talvez noutra matéria".

JoÃo Mendes Junion foi um professor, grande professor, da estirpe de Brotero, de Crispiniano, de Justino, de Ramalho, de João Monteiro, de Brasilio Machado.

Senhor de incomparavel ciência juridica, que o estudo diuturno alargava e os conhecimentos filosóficos tornavam mais profunda, as suas preleções, não obstante certa dificuldade de falar, eram modelares. Não divagava. Não perdia tempo no acúmulo de definições inúteis, em regra levantadas para serem sucessivamente demolidas. Expunha a materia sem exibicionismo de livraria. Explicava-a com segurança, fórma precisa, técnica insuperavel. Pureza de linguagem. Firmeza de dialetica. Clareza. Elegância da fráse. Correção. As notas, que os alunos costumavam tomar, tornavam-se dificeis, porque, realmente, era impossivel tornar mais simples o que ele, com tanta simplicidade, prelecionava. Não disperdiçava palavras. Proferia as exatamente necessarias para exprimir as suas ideias, pondo-as ao alcance das inteligências mais pálidas.

Os que, no ultimo ano acadêmico, se habituaram a ouvir-lhe as lições, não somente não as esqueceram, como, na vida prática, encontraram o mestre sempre solicito no reproduzí-las, resolvendo as suas dificuldades de doutrina $e$ de processo. Mestre na Academia, mestre fóra da Academia, foi o maior jurisconsulto de nosso tempo, ouvido e acatado por todos nós. Os seus livros de direito, todos os 
dias citados nos pareceres, nas monografias, nos tratados, nos arrazoados forenses, nas sentenças, nos acórdãos, são obras clássicas, que o colocaram no mesmo plano de TEIxeira de Freitas, de Lafayette, de Ramalho.

\section{SÃO PAULO NO SUPREMO TRIBUNAL FEDERAL}

Quando, pois, reproduzindo o gesto de Afronso Penna, que levara Pedro Lessa desta Academia para o Supremo Tribunal Federal, Wenceslau Braz aqui veiu buscar João Mendes, para dar-lhe lugar naquele areopágo, isso causou, entre nos, surprêsa e satisfação.

Surprêsa porque, em regra, para o Supremo Tribunal Federal eram, de preferência, nomeados os chefes de policia da Capital Federal e os ministros de Estado em vésperas de afundarem-se no ostracismo politico. Surprêsa porque, embora sendo dos maiores centros de cultura juridica, São Paulo, que adotou, de ha muito, o princípio - que deve ser posto à margem - de não disputar cargos para os paulistas, na Federação, não teve a fortuna de contribuir, para a formação do Supremo Tribunal Federal, na proporção de seus recursos. Dos sessenta e tres brasileiros nomeados para a nossa mais alta côrte de Justiça, desde o Visconde DE Sabará a Arthur Ribeiro, apenas seis, se não estou em êrro, foram de São Paulo. Tres foram do Tribunal de Justiça de S. Paulo, corporação de magistrados que, pela sua integridade e pelo seu saber, faria a honra de qualquer país, e cujas decisões são comentadas e acatadas em todo o cósmos juridico brasileiro. Tres foram desta Academia de Direito. Nenhum (e diga-se esta verdade em abono da politica paulista!) para ali foi pela estrada estreita e, muitas vezes, tortuosa dos interesses partidários.

Quando, em 1890, se constituiu o Supremo Tribunal, daqui foi Jonquim de Toledo Piza e Almeida, cujo nome recordo, com prazer, neste momento, e cujo perfil RuY BarBosA traçou assim: 
"Singularidade notavel que São Paulo, a escóla mais aspera do partidarismo militante e o mercado mais ativo da transação politica entre nós, seja tambem o berço do tipo mais completo de julgador, que já se assinalou em nossa historia. E, a meu ver, a produção deste modelo, já classico, das virtudes da justiça, honra ele só infinitamente mais aquele opulento viveiro das forças do trabalho entre nós do que todos os seus homens politicos reunidos".

"Como aquele personagem de Shakespeare, capaz de reconhecer ao proprio demônio o seu direito, o grande brasileiro já não é, para nós, uma opinião: é uma escola; já não é uma individualidade: é a propria justiça".

"Sua presença embalsâma o tribunal, a que pertence, e redime as nódoas do seu tempo. No meio dos verdadeiros republicanos, a sua imagem entrará na familia de todos, de cada lar se evolará por ele uma benção, e cada um de nossos filhos o apontarả como um patriarca".

Da Congregação dos Professores desta Faculdade veiu Floriano Peixoto, em 1894, retirar Americo Brasiliense de Almeida Melo, por tantos e valiosos titulos insígne, no saber e na honra. Formado nesta casa em 1855 e doutorado em 1860, encetou sua advocacia em Sorocaba, onde ascendeu à chefia do partido liberal, que o trouxe para a Assembléia Geral Legislativa, tendo seu mandato renovado em diversas legislaturas. Presidente da Paraíba em 1867, do Rio de Janeiro em 1868, instalou-se em seguida em Campinas, onde se ientregou à propaganda abolicionista e republicana, e exercitou o magistério secundário, de que resultaram as suas Lições de História Patria. Sinatário do manifesto republicano de 1870, destacou-se como publicista, editando, em 1878, Os Programas dos Partidos e o Segundo Império. Lente substituto deste estabelecimento em 1882; catedrático ,de direito romano em 1888 e de direito das gentes, diplomacía e história dos tratados em 1890; relator por convite de Prudente de Morais, de projeto de constituição politica da República; resignatário dos cargos de Ministro da Fazenda 
e de Ministro do Brasil em Portugal, e de presidente de São Paulo, em 1892, tinha os mais altos brazões para ser, como foi, no Supremo Tribunal Federal, juiz incorruptivel, de austera dignidade e grande nobreza.

Na presidencia Rodrigues Alves, em 1903, o nomeado foi Pedro Antonio de Oliveira Ribeiro, então ministro do Tribunal de Justiça de São Paulo, natural de Laranjeiras, Sergipe, personalidade invulgar. Representou a sua cidade na Câmara Estadual, o seu Estado na Câmara dos Deputados, depois de ter exercido a magistratura em seu Estado e no de Minas Gerais. Chefe de policia da Capital Federal, nos governos de Deodoro da Fonseca e de Floriano Peixoto; chefe de policia desta capital e procurador geral do Estado, bem mereceu o cargo, ao qual deu o melhor de sua inteligência e do seu patriotismo.

Em 1907, aqui veiu Affonso Penna buscar Pedro Lessa, que ensinava filosofia de direito nesta Academia, e era advogado dos mais notaveis do Brasil. Nascido na pequena cidade do Serro, onde tambem nasceu Edmundo Lins, Pedro Lessa fez os seus estudos nesta cidade e aqui formou o seu espírito, constituiu familia, fez-se advogado e professor de direito, abrindo, novos horizontes para a materia que prelecionava, com tal superioridade, que, a bemdizer, ele criou cadeira nova, pela originalidade que pôs no seu ensino. Foi, sobretudo, um forte, varão insigne, padrão de homem de honra, mestre de civismo.

Em 1908 a nomeação para o Supremo Tribunal Federal recaíu no ministro do Tribunal de Justiça de S. Paulo, CAnuto José Saraiva, natural de Arêias, a antiga cidade paulista. Do que foi o magistrado e do que foi a sua judicatura, eis o testemunho de Pedro Lessa:

"Retraído e de tudo afastado, de uma modestia invencivel, visceral, de uma serenidade que nada perturbava, a vida para ele se resumiu toda no estudo das questões que, como juiz, devia julgar, e na idolatría da família, que generosamente lhe compensou tanto amor, apresentando-se-lhe 
e à sociedade, cada um dos seus membros, como um modelo inexcedivel de correção moral. Para as soluções, que dava aos litigios, sujeitos ao seu julgamento, só concorreram sempre o seu critério, o seu saber jurídico, a sua integridade e o seu carater sem mácula e sempre igual, e nenhuma influência acidental, estranha à sua concepção jurídica, às suas convicções, às suas ideias".

"Quando faleceu o grande juiz, que foi Piza e Almeida, o saudosissimo presidente Afronso Penna, um protótipo de homem de bem, timbrou em dar-lhe um sucessor, que fosse digno do ilustre morto. Nomeou então Canuto Saraiva, e todos aplaudiram a escolha, reconhecendo que a vaga de Piza e Almeida fôra preenchida".

"E' este o seu melhor elogio".

A nomeação de João Mendes Junior veiu encher-nos de júbilo.

Porque ele era o cidadão de notavel saber e reputação, como o exige a carta republicana, digno, portanto, de formar entre os quinze juizes aos quais ela deu a atribuição quasi divina de distribuir justiça, mantendo, com a unidade do direito substantivo, a unidade nacional, formando a cúpola dos três poderes.

Porque ele havia de manter, e manteve, no Supremo Tribunal Federal, a tradição de saber e de honra dos poucos mas grandes juizes, que São Paulo the deu.

\section{O MAGISTRADO}

Simples, modesto, conhecedor da falacidade humana, psicólogo, filósofo, jurista, sem paixões, sem ódios, sem malquerênças, bom, positivamente bom, Joño Mendes Junior havia de ser, como foi, a encarnação da justiça.

Prolongou, na magistratura, o seu magistério. Continuou a ser ali, como aqui, o professor de direito, aplicando aos casos concretos os princípios gerais, a doutrina, que aqui 
expendeu, certo, como estava, de que a missão do juiz é bem maior e muito mais nobre do que a de proferir, mecânicamente, despachos e sentenças, tenções e acórdãos. Juiz não é máquina de despachar e de sentenciar, restrita a sua ação à controversia dos feitos. Ele tem tambem função social, papel político, no mais elevado sentido desta expressão, como membro de um dos poderes politicos do estado moderno.

Estudos recentes, lê-se num livro de Pietro Cogliolo, mostram que a evolução jurídica não começa, nem com a lei, nem com os costumes, mas com a sententia judicis: apenas se apresenta consórcio humano, na história, com as primitivas condições de certa jerarquia, verifica-se que as contêndas privadas deixam de ser resolvidas com as armas e com o sangue e passam a ser decididas pelo chefe da tribo, pelo pai de família, pelo sacerdote, ou pelo rei. A primeira fonte de direito é, pois, a sentença do juiz: vem depois, para tornar solidos os costumes, a lei. Bem disse Grotius que Zeus, rei na terra, não é legislador, mas juiz e em Homero não se encontra a palavra nómos, ou lei. A justiça é indicada pela palavra themisthes, isto é, sentença dada pela divindade aos juizes. Mesmo nos períodos de civilização e de maior e pleno desenvolvimento jurídico, as sentenças dos magistrados tiveram sempre parte criadora, superando o simples e imediato escôpo de dirimir litigios. Quem sabe quanto operou sobre o direito romano o edíto dos pretores e quanto foi esse edíto a súmula das fórmulas e normas contidas nas decisões singulares; quem conhece a influência que, na época medieval, teve a jurisprudência sobre o direito; quem tem exata noção destas e de outras coisas afins, concluiu Cogliolo, compreenderá que a sentença do juiz é não somente a decisão de lide particular, mas tambem fonte de produção jurídica.

Tivesse João Mendes JunIor ou não, idêntico conceito, o que de sua obra de magistrado se infere é que, aprofundando o estudo do direito nacional, conhecendo, como a palma de sua mão, os civilistas daquem e dalém mar, os assêntos 
mais antigos, velhas ordenações, ele mesmo decidindo litigios entre particulares, trabalhou quanto poude por fazer do direito o que ele deve ser: fatôr de integração nacional. Tradicionalista, passadista, como hoje se diz, tinha a convicção de que não póde haver progresso sem continuidade de tradição. Não ha arvore, por mais alta e frondosa, que não afunde mais e mais as suas raizes, à proporção que se vai elevando, acima do solo, para extrair, das profundidades do sub-solo, bem fresca, a seiva com que alimente os seus ramos. Um pais sómente poderá desenvolver-se, na continuidade do seu passado, conservando o útil, retocando o que carecer de melhoria, em marcha ascencional, mas equilibrada, para que, nas refórmas, não se ouçam, como João Mendes Junior dizia, "vozes dos tumulos, como veementes protestos das gerações que se foram".

Homem de conciência e de fé, manteve as suas crenças, nelas adoçou o seu temperamento, cheio de carinhos e de ternuras, alma fervorosa de cristão, que não vacilou no cumprimento de seu dever e que o levou, no mais alto tribunal brasileiro, a fazer justiça, com o mesmo sereno desassombro com que fazia as suas práticas religiosas, tendo diante dos olhos não o interêsse das partes, mas a lei e, acima dela, Deus, em que se polarizam, na frase do poeta, como bússolas radiosas, todas as grandes almas.

Encerremos esta oração.

A obra de Joño Mendes de Almeida Junion é de hoje. Ela aí está para justificar a homenagem que lhe presta o Instituto da Ordem dos Advogados de São Paulo, trazendo para este salão nobre, povoado de figuras venerandas e sagradas para o nosso amor e para a nossa historia, o busto, em bronze, daquele homem puro, mestre dos que foram mestres, juiz que foi justo.

Colocando neste recinto de meditação, em que as gerações se renovam, aquela cabeça de sábio antigo, que o talento de um moço reproduziu com tanta fidelidade, esperemos que o tempo, aureolando-a com a sua poeira de ouro, 
lhe dê os tóques misteriosos, com que a sua pátina convérte os homens em númes tutelares. .

Discurso do professor Spencer Vampré:

"Senhores - Bem escolhestes a solenidade de hoje para ofertar a esta Faculdade os bustos de PeDro Lessa e JoÃo Mendes Junior. A presença do ilustre embaixador da Republica Argentina, que tão bem encarna os sentimentos cavalheirosos de sua grande patria, a querida nação argentina, e que, ao mesmo tempo, fulge, como eminente professor de sua principal Universidade, fôra, por si só, bastante a demonstrar o acerto de vossa escolha.

Mas, a festa simbólica da chave constitue segundo motivo, para que a preferência por este dia se patentêie sobremodo feliz.

Tudo no Universo é simbolo. Por toda a parte espalhou a Providência os atestados do seu poder e da sua imensa sabedoria: - na via látea, a cintilar sobre as nossas cabeças, no sentimento do dever, a palpitar dentro de nossos peitos; na marcha dos órbes, acorrentados ás leis de KePEER e de Newton; no progresso das idéias morais, orientadas. pelos pensadores, pelos jurisconsultos e pelos santos.

E si a marcha dos órbes, jungidos á imutabilidade de suas leis, constitúe um dos mais maravilhosos espetáculos de criação, o evoluir da idéia e do sentimento da justiça, através dos dramas da historia, não lhe fica somênos, perante a admiração humana.

Esta chave, na humildade grosseira de sua fórma, simboliza a tradição e o progresso.

A nova geração acadêmica recebe, alviçareira, o legado precioso da geração que a precedeu; e a chave simbólica assim fecha, e assim abre, uma época que passou e uma fase que se vai descerrar. Ela é o passado e o futuro; o que já foi e o que ha de ser; a saudade e a esperança; a noite e a aurora; os sonhos irrequietos da mocidade, que acórdam na 
realidade grosseira da vida; o túmulo dos devanêios que morrem, e o berço azul onde nasce a inspiração nova.

Definiu-a, a esta solenidade, João Mendes Junıor, como festa simbólica da atenção. Para o grave filosofo, a chave concretiza a atenção, dirigida pelo método, até a torre de marfim, onde mora a verdade. E cada geração, que passa, entrega á seguinte a chave da época nova que se vai abrir para a ciência e para a humanidade.

Festa do coração, puderamos chama-la, porque em tudo úne a mocidade a generosidade da alma aos vôos ambiciosos da mente; os moços pensam com o coração, como os velhos se emocionam com o cérebro.

Festa do coração, puderamos chama-la em todas as épocas, porque a fraternidade acadêmica se firma através dela, e fulge, e cintíla, e alumia aqueles mesmos que, como vós, pertencestes, alunos, a esta casa, e continuais a pertencerlhe pela admiração e pela saudade.

Festa do coração, puderamos chama-la hoje, melhor do que nunca, porque quizestes unir, delicadamente, o vosso culto ao nosso; e à mocidade cheia de esperança quizestes associar o perfume de vossas recordações.

Que digo? Quizestes reviver comnôsco essas horas sagradas e inesqueciveis, que são o melhor de vossa vida, porque são a vossa mocidade que passou, ou que vai passando; quizestes entrar, de novo, neste recinto, onde ecôam as vozes gloriosas que, ha um seculo, apontam a esta Academia os seus destinos historicos, e quizestes sonhar com a brilhante mocidade acadêmica os sonhos de glória do nosso grande Brasil.

De glória, sim! Não da glória, entretecida de injustiças, e ensopada de sangue, das nações imperialistas; não da glória futil, que deshonra a humanidade em conquistas territoriais; não da gloria falaz, que apenas visa hegemonias fundadas na força.

Mas, da gloria pacifica e conciente do Brasil, unido fraternalmente às demais nações americanas, no culto indefêsso da justiça internacional, para que a America continúe a 
orgulhar-se de dar ao mundo as mais belas lições de democracia e de idealismo!

Quizestes sonhar o Brasil, erguendo a cabeça, no sêio das nações, não pelo numero de seus soldados, nem pelo calado de seus navios, mas pelo alto e nobre espirito de justiça, que é uma tradição gloriosa das diplomacias americanas, ante a qual ferozes e impotentes se embatem os que empreitam guerras, com a mesma perversidade com que envenenam a opinião publica, de países irmãos pela fatalidade geográfica e historica, e, mais do que isso, irmãos pela convergência de seus destinos, e pela sinceridade com que se respeitam e se amam.

E, como a conduta de hoje é o reflexo dos sentimentos de ôntem, quizestes trazer por penhor de vosso afeto, duas lembranças, que hão de recordar sempre o vosso gesto generoso, e os sentimentos que o ditaram/: - os dois bustos de Pedro Lessa e João Mendes Junior hão de ficar aqui, na memória desta Academia, não já apenas como simbolos destes dois grandes mestres, mas tambem como fórmas materializadas de vossa saudade e do vosso devotamento a esta casa, e ao Brasil.

Assemelham-se, nos grandes traços, essas duas pujantes personalidades, tanto quanto se distanciam quando os consideramos de mais perto.

Ambos, bachareis por esta Faculdade, João Mendes em 1877, Pedro Lessa, seis anos mais tarde, em 1883. Recebe o primeiro o titulo de doutor, dois anos depois da formatura; este, logo no ano seguinte à láurea.

Em denodados concursos, grangêiam, um e outro, nomeações de substituto: JoÃo Mendes Junior, dias antes da proclamação da Republica; Pedro Lessa, um ano e tanto antes dela.

$\mathrm{Na}$ cátedra luzem ambos pelos dotes incomparáveis do espírito: em Pedro Lessa, o ardor das convicções, a largueza das téses, os vôos de condôr de uma mentalidade regorgitante de força; em JoÃo Mendes Junıor, a dialética sutíl, a análise profunda das fontes, unida à sagacidade escolás- 
tica, na sua maxima agudeza. Em Pedro Lessa o doctor magnificus, em Jỗo Mendes Junior o doctor subtilis.

Depois, como si a Providência quizesse colocá-los em sólio mais alto, para que de mais alto irradiassem a luz do seu engenho sobre a nação inteira, ei-los, ambos, nomeados Ministros do Supremo Tribunal Federal.

Até aqui as semelhanças, que a um e outro engrandecem. Agora as diferênças, que a um e outro singularizam.

Pedro Lessa, juiz, foi sempre mais professor do que juiz; Joño Mendes Junion, professor, foi sempre mais juiz do que professor.

Em Pedro Lessa, a paixão doutrinária levava-o a considerar quasi como questões pessoais pontos de vista doutrinários; em JoÃo Mendes JUnIoR, a mais profunda tolerância científica se irmanava a convicções arraigadas. Aquele, espirito aberto a todos os horizontes especulativos, não sofria que lhe tolhessem as azas ao voejar da mente; este, aferrado ao tomismo, deixava que o antagonista alinhasse livremente as suas fileiras, para varre-las com a metralha das distinções escolásticas.

Pedro Lessa personalizava o espírito novo, influenciado por Comte, Stuart Mill, Sumner Maine e Ihering; João MenDES Junior refletia o genio dos glosadores e dos praxistas, revolvendo, desembaraçado e infatigavel, textos e opiniões, contêndas históricas ha muito esquecidas, e expressões legais ininteligiveis para muitos.

Aquele, com vôo de águia, pairava sobrancêiro numa atmosfera banhada do clarão do sol. Este, garimpeiro indefêsso, extraia o véio aurífero, com tenacidade de bandeirante.

Não admira, pois, que a obra prima de Pedro Lessa seja a Filosofia do Direito, como a de JoÃo Mendes Junion, o Processo Criminal Brasileiro.

Publicadas, tiveram logo os fóros de classicas, e classicas ficarão, para gloria deles e nossa.

A verdadeira gloria não é a que cérca o homem de gênio neste mundo; mas a que começa a lhe florir sobre o túmulo. 
As glorias da vida, perde-as o homem com a vida: "Cum interieret, non summet omnia, neque descendit cum eo gloria ejus" (Psalmo, 48, vers. 18).

Mas, as palmas que nascem da gratidão da posteridade são alguma coisa mais que "o triste privilegio de ser feliz pelo testemunho alhêio".

Bem avisados andastes, meus senhores, ao querer que estes bustos fossem uma gloriosa e perene lição aos moços academicos. Pedro Lessa e JoÃo Mendes Junior assistirão, de hoje em diante, todos os anos, a festa da chave - noite para uns e aurora para outros, túmulo de sonhos juvenis, berço de saudades.

E como prêmio à generosidade do Instituto dos Advogados de São Paulo, e dos amigos de Pedro Lessa, inspirem as duas grandes figuras a mocidade estudiosa, para gloria do Brasil e da America! 